\title{
O DESENVOLVIMENTO DE UM MODELO DIALÓGICO DE PLANEJAMENTO DE PROJETOS DE PESQUISA PARA ESTUDANTES DOS ANOS FINAIS DO ENSINO FUNDAMENTAL
}

\section{THE DEVELOPMENT OF A DIALOGICAL MODEL FOR THE PLANNING OF RESEARCH PROJECTS FOR MIDDLE SCHOOL STUDENTS}

\author{
Jonathan Zotti da Silva* \\ Mônica da Silva Gallon **
}

\section{RESUMO}

As feiras de ciências impulsionam pesquisas científicas na escola. Como o conhecimento científico é privilegiado neste tipo de evento, os projetos mais prestigiados são os que resultam de uma investigação sistemática. Com o desafio de viabilizar o processo de planejamento de projetos investigativos em uma escola pública de Canoas (RS), este trabalho tem o objetivo de propor um modelo dialógico de planejamento de projetos de pesquisa para estudantes dos anos finais do ensino fundamental. A partir da perspectiva dos letramentos acadêmicos (LEA; STREET, 1998), o modelo apresentado neste artigo busca esclarecer aos estudantes aquilo que conta como conhecimento em determinada área e como isso aparece na escrita do projeto. Seguindo princípios da avaliação formativa (BLACK; WILIAM, 1998), foi elaborado um quadro com descritores avaliativos dos elementos de um projeto de pesquisa. Essa estratégia concebe os estudantes como protagonistas do processo de aprendizagem e também de avaliação, pois permite que eles saibam como serão avaliados de antemão e o que devem fazer para atingir os objetivos estabelecidos. Além disso, os estudantes também podem atuar como leitores interessados dos projetos uns dos outros, avaliando-os conforme os descritores e escrevendo pareceres como forma de feedback.

Palavras-chave: projetos de pesquisa; letramentos acadêmicos; avaliação formativa.

\section{ABSTRACT}

Science fairs boost scientific research at school. Since scientific knowledge is privileged in this kind of event, the most prestigious projects are the ones that result from a systematic investigation. In order to enable the planning of investigative projects in a public school of Canoas (RS), this paper aims to propose a dialogical model for the planning of research projects for middle school students. From the academic literacies perspective (LEA;

\footnotetext{
* Universidade Federal do Rio Grande do Sul (UFRGS), Porto Alegre, RS, Brasil. jonzsilva@gmail.com, https://orcid.org/0000-0001-8169-8540

** Pontifícia Universidade Católica do Rio Grande do Sul (PUCRS) , Porto Alegre, RS, Brasil. monica. gallon@gmail.com, http://orcid.org/0000-0003-0793-2372
} 
STREET, 1998), the model proposed here seeks to clarify to students what counts as knowledge in a certain area and how it appears in the writing of the project. According to the principles of formative assessment (BLACK WILIAM, 1998), it was developed a rubrics framework for the elements of a research project. This strategy sees students as protagonists of learning and assessment processes because it allows them to know beforehand how they will be evaluated and what they have to do to achieve the stated goals. In addition, students can also act as concerned readers of each other's projects, grading them according to the rubrics framework and writing opinions as a form of feedback

Keywords: research projects; academic literacies; formative assessment.

\section{INTRODUÇÃO}

A pesquisa na escola tem sido impulsionada pelas feiras de ciência. As feiras, por vezes também chamadas de mostras, são entendidas como eventos em que o termo ciências deve ser percebido "no seu sentido mais amplo, referindose muito mais à pesquisa científica em qualquer ciência" (MANCUSO; LEITE FILHO, 2006, p. 17, grifo dos autores). Com o movimento ganhando força no Rio Grande do Sul e no Brasil, uma escola pública do município de Canoas propõe que os alunos dos anos finais do ensino fundamental se envolvam em projetos de iniciação científica e apresentem os resultados de suas pesquisas em uma feira de ciências. Esse evento pode ser definido como "um processo de culminância dos trabalhos escolares realizados durante certo período letivo" (GONÇALVES, 2011, p. 207). Em outras palavras, a feira é um produto da realização de projetos desenvolvidos ao longo de meses de trabalho conjunto entre alunos e professores, sendo esse um momento para o compartilhamento dos achados de pesquisa, expondo às críticas de diferentes públicos .

Antes de executar as pesquisas, os estudantes, em grupos, sob orientação de um professor, são requisitados a produzir um projeto de pesquisa. Ribeiro (2015), ao descrever os tipos de trabalho que podem ser apresentados em feiras de ciências, sugere que os projetos investigativos sejam preferidos em relação aos projetos demonstrativos. O autor afirma que os estudantes aprendem realizando esses trabalhos; no entanto, argumenta que "não se pode negar, porém, a grande diferença que há entre demonstrar algo já existente e construir o próprio conhecimento" (RIBEIRO, 2015, p. 40). Além disso, dentre as dez competências gerais elencadas na Base Nacional Comum Curricular (BNCC), há uma orientação clara para o exercício da pesquisa científica:

Exercitar a curiosidade intelectual e recorrer à abordagem própria das ciências, incluindo a investigação, a reflexão, a análise crítica, a imaginação e a criatividade, para investigar causas, 
elaborar e testar hipóteses, formular e resolver problemas e inventar soluções com base nos conhecimentos das diferentes áreas (BRASIL, 2017, p. 18).

Nesse processo de investigação na escola, há também uma reconfiguração do papel do professor, que já não passa mais a ser visto como detentor do conhecimento, mas, sim, como orientador, participando conjuntamente do processo de construção de novos saberes ao lado do aluno. Assim, o processo de planejamento e execução de projetos também é uma oportunidade para que os professores desenvolvam atributos importantes para o bom desenvolvimento da pesquisa na escola. Nesse sentido, compreendemos como Gallon, Silva e Madruga (2018, p. 167), compreendemos que "a pesquisa em sala de aula é uma estratégia de ensino e aprendizagem que propõe reconstrução de saberes, autonomia e protagonismo não apenas aos estudantes, mas também aos professores que se envolvem no processo". A formação de um professor orientador se dá na prática, orientando projetos dos alunos. Daí surge a necessidade do desenvolvimento de propostas e materiais que viabilizem esse trabalho, especialmente no que se refere à operacionalização do planejamento e da execução dos projetos de pesquisa.

Apesar dessas indicações sobre investigação científica, não existem trabalhos que investiguem ou proponham o processo de escrita de projetos de pesquisa, considerando a interação entre professor e aluno. Gallon, Rocha Filho e Nascimento (2017), em um levantamento de trabalhos apresentados nos Encontros Nacionais de Pesquisa em Educação em Ciências (ENPECs) que de alguma forma abordavam as feiras de ciências em suas pesquisas, notaram que apenas dois trabalhos dos 24 trabalhos selecionados tinham seus objetivos centrados nos estudantes enquanto pesquisadores. Assim, o trabalho dos autores corrobora a demanda de produção de conhecimento sobre esse processo de pesquisa centrado no aluno, constatando "a necessidade de estudos que enfoquem nas etapas da pesquisa em sala de aula, como forma de compreender e ampliar as aprendizagens dos estudantes potencializando seus projetos e fazendo-os perceber-se e refletir como também sujeitos de uma pesquisa" (GALLON; ROCHA FILHO; NASCIMENTO, 2017, p. 8).

Considerando que a projeção de uma pesquisa constitui uma etapa essencial para a investigação científica, este trabalho busca propor um modelo dialógico de planejamento de projetos de pesquisa para estudantes dos anos finais do ensino fundamental. Para isso, retomamos nas próximas seções os conceitos de letramentos acadêmicos (LEA; STREET, 1998) e avaliação formativa (BLACK; WILIAM, 1998) a fim de desenvolver uma ficha para elaboração dos projetos que explicite os parâmetros avaliativos de cada parte da pesquisa. 


\section{LETRAMENTOS ACADÊMICOS}

Os usos acadêmicos da leitura e da escrita têm sido objeto de pesquisa dos estudos de letramento no âmbito do ensino superior. Diversas pesquisas no campo voltam-se ao discurso do déficit, que afirma que os estudantes chegam à universidade sem saber ler e escrever (LEA; STREET, 1998). Esse discurso é problemático, pois se baseia no modelo de letramento autônomo (STREET, 1984), que compreende o letramento como um conjunto de habilidades as quais podem ser aprendidas e aplicadas a todos contextos. Normalmente é essa concepção de letramento que orienta o processo de escolarização. Se a universidade entende que letramento é um conjunto universal de habilidades, então os alunos que não as dominam estão em déficit. Em contrapartida, Street (1984) desenvolveu o conceito de letramento ideológico, que compreende letramento como prática social. Mais culturalmente sensível, esse modelo entende que as práticas de letramento variam de um contexto para outro. Nessa perspectiva as pessoas chegam à universidade após diversas experiências com práticas de letramento; estas podem ou não ser aquelas demandadas no ensino superior. Nesse sentido, Fischer (2007) buscou apresentar um modelo de letramento na esfera acadêmica que não negue as práticas sociais de linguagem vivenciadas na escolarização básica dos estudantes, mas que, a partir delas, negocie novas práticas sociais e identidades propostas pelo meio acadêmico.

Ao estudarem as abordagens institucionais da escrita acadêmica, Lea e Street $(1998,2006)$ descreveram três modelos de aprendizagem: o modelo de habilidades de estudo (study skills), que compreende a escrita como uma habilidade cognitiva individual e foca nos aspectos formais da língua. A premissa desse modelo é que, depois de aprendidos, os estudantes podem transferir, de um contexto para outro, os conhecimentos sobre escrita e letramento sem nenhum problema (LEA; STREET, 2006). Mais epistemologicamente associado ao letramento autônomo (STREET, 1984), tal modelo de aprendizagem pretende resolver os problemas da escrita dos estudantes, buscando desfazer o déficit.

O segundo modelo é chamado de socialização acadêmica (academic socialization), que compreende a academia como uma cultura na qual os estudantes devem ser inseridos. Nessa perspectiva a cultura acadêmica é relativamente homogênea; assim, bastaria que os estudantes aprendessem jeitos de falar e escrever da academia para poder circular por todas áreas do conhecimento (LEA; STREET, 1998). O terceiro e último modelo é o de letramentos acadêmicos (academic literacies), que, assim como na perspectiva ideológica de letramento (STREET, 1984), compreende o letramento acadêmico como prática social. Esse modelo busca evidenciar aquilo que 
conta como conhecimento para um contexto acadêmico específico (LEA; STREET, 2006). É similar ao modelo de socialização acadêmica, porém compreende que os usos efetivos do letramento são mais complexos e situados. Assim, na perspectiva do estudante, algumas das características dominantes do letramento são "alternar as práticas conforme o ambiente, desenvolver um repertório de práticas linguísticas apropriados para cada ambiente e lidar significados e identidades sociais que cada

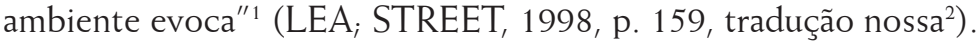

O presente estudo busca dialogar o modelo de letramentos acadêmicos com a educação básica, mais especificamente com os anos finais do ensino fundamental. Nesse sentido, Lea e Street (2006, p.368) afirmam que, "embora o termo 'letramentos acadêmicos' tenha sido originalmente desenvolvido no que diz respeito ao estudo dos letramentos no ensino superior e na universidade, o conceito também se aplica da educação infantil ao ensino médio"3. Sendo assim, a partir da compreensão de que os letramentos acadêmicos interpretam a escrita de modo mais situado, identificando aquilo que conta como conhecimento em determinado ambiente acadêmico, este artigo discute como didatizar e tornar explícito os elementos de um projeto de pesquisa na educação básica.

\section{AVALIAÇÃO FORMATIVA}

É comum que as práticas avaliativas sejam pensadas "como forma de manutenção do poder do professor e como instrumento de punição, para disciplinar os alunos" (RIO GRANDE DO SUL, 2009, p. 165). Esses dois valores somados a uma avaliação centrada nos resultados de uma prova costumam fazer com que ser avaliado seja uma experiência negativa, causando medo e resistência às metas educacionais. Gonçalves et al. (2007), sustentam que essa concepção de avaliação privilegia a dimensão técnica ou burocrática ${ }^{4}$, com a função de regular os resultados obtidos em um recorte específico do tempo escolar, como um trimestre ou ano escolar, certificando se o estudante será promovido ou reprovado. Por outro lado, Gonçalves et al. $(2007$, p.7) apontam que as avaliações escolares também podem apresentar uma dimensão formativa, com uma função "diagnóstica, processual, descritiva e qualitativa, capaz de indicar os níveis já consolidados pelo aluno, suas

1. To switch practices between one setting and another, to deploy a repertoire of linguistic practice appropriate to each setting, and to handle the social meanings and identities that each evokes.

2. Essa e todas as traduções deste artigo foram realizadas pelos autores.

3. Although the term academic literacies was originally developed with regard to the study of literacies in higher education and the university, the concept also applies to $\mathrm{K}-12$ education.

4. Também chamada de avaliação somativa (BLACK, WILIAM, 1998). 
dificuldades ao longo do processo e as estratégias de intervenção necessárias a seus avanços". Uma avaliação que contempla a dimensão formativa deve estar a serviço da aprendizagem dos alunos, diagnosticando o quanto das metas de aprendizagem foram atingidas e subsidiando professores e alunos para tomar decisões quanto às ações necessárias. Ambas dimensões não são necessariamente excludentes, pois cada uma tem sua função na avaliação escolar. $O$ problema está no fato de que a dimensão burocrática historicamente tem sido privilegiada em detrimento do desenvolvimento da aprendizagem do estudante.

Com base na revisão de literatura realizada por Black e Wiliam (1998), Sadler (1998, p. 77) define avaliação formativa como "avaliação que se destina especificamente a fornecer feedback sobre o desempenho para melhorar e acelerar a aprendizagem ${ }^{\prime \prime}$. Nessa concepção de avaliação, o fornecimento de feedback tem um papel central, pois é a partir dele se torna possível informar se os aspectos valorizados em determinada tarefa estão sendo abordados e como ajustar a aprendizagem para contemplá-los. Wiliam (2007, p. 1065) afirma que "a grande ideia [da avaliação formativa] é que a evidência sobre a aprendizagem do estudante é utilizada para adequar a instrução para melhor atender a necessidade dos estudantes" ${ }^{\prime \prime}$. Além do feedback, a adaptação das práticas instrucionais para favorecer a aprendizagem é uma característica da avaliação formativa. Nessa perspectiva o termo instrução se refere a qualquer atividade realizada com objetivo de aprendizagem, seja nos processos de ensino ou nos processos de aprendizagem.

Em estudo posterior, Black e Wiliam (2009, p. 8) propõem uma teoria de avaliação formativa baseada na prática. Nesse sentido, os autores estabelecem cinco estratégias que fundamentam essa concepção de avaliação:

1. Esclarecer e compartilhar os propósitos de aprendizagem e critérios para sucesso;

2. Desenvolver discussões eficazes em sala de aula e outras tarefas de aprendizagem que indiquem evidências da compreensão do aluno;

3. Fornecer feedback para que os alunos progridam;

4. Tornar os alunos recursos instrucionais uns para os outros; e

5. Tornar os alunos donos da sua aprendizagem. ${ }^{7}$

5. Assessment that is specifically intended to provide feedback on performance to improve and accelerate learning.

6. The big idea is that evidence about student learning is used to adjust instruction to better meet student needs.

7. 1. Clarifying and sharing learning intentions and criteria for success; 2 . Engineering effective classroom discussions and other learning tasks that elicit evidence of student understanding; 3 . Providing feedback that moves learners forward; 4 . Activating students as instructional resources for one another; and 5. Activating students as the owners of their own learning. 
As diversas práticas de avaliação formativa podem ser interpretadas como maneiras de operacionalizar essas cinco estratégias ${ }^{8}$. Conforme será discutido posteriormente, no processo de escrita e reescrita dos projetos de pesquisa no contexto de anos finais do ensino fundamental, todas estratégias podem ser contempladas em maior ou menor grau.

\section{DESCRITORES AVALIATIVOS PARA UM PROJETO DE INICIAÇÃO CIENTÍFICA}

Com base em Clark (2000), Dilli, Schoffen e Schlatter (2012, p. 172) utilizam uma concepção de uso da linguagem, "que compreende as práticas sociais como construídas na ação conjunta dos participantes em uma situação de comunicação com um determinado propósito negociado por eles". Nessa concepção de língua, a comunicação humana ocorre por meio de gêneros do discurso, que, nas palavras de Bakhtin (2003, p. 279), são "tipos relativamente estáveis de enunciados", que são definidos pelas condições de produção em cada esfera da atividade humana.

Considerando a iniciação científica na educação básica como uma esfera da atividade humana, um projeto de pesquisa é um dos gêneros do discurso que circula em tal esfera. Quando se propõe que o gênero projeto de pesquisa seja objeto de aprendizagem e, consequentemente, de avaliação, cria-se a necessidade de se elaborar parâmetros para que alunos e professores possam escrever e avaliar projetos. Além disso, explicitar esses parâmetros é essencial para uma boa avaliação. Schlatter e Garcez (2012, p. 161) afirmam que "essa explicitação orienta os alunos e o professor no desenvolvimento do projeto, pois desde o início é possível saber as linhas gerais do que é esperado de cada um e o que é necessário em termos de condições para levar o projeto a cabo". É nesse sentido que este artigo propõe descritores para guiar os processos de escrita e reescrita e de avaliação.

Reddy e Andrade (2010, p. 435) definem descritores como "um documento que articula as expectativas para uma tarefa ao listar critérios ou o que conta e descreve níveis de qualidade, de excelente a ruim" ${ }^{\prime \prime}$. Segundo esses autores, os descritores possuem três características essenciais: (1) critérios de avaliação, que são os fatores que serão levados em conta ao determinar a qualidade de um trabalho, aparecendo muitas vezes em forma de lista de diretrizes; (2) definições de qualidade, que tem o objetivo de explicar detalhadamente o que deve ser feito para demonstrar determinada habilidade ou conhecimento, servindo para pontuação e

8. Wiliam (2011) explora detalhadamente cada uma dessas estratégias.

9. A document that articulates the expectations for an assignment by listing the criteria or what counts, and describing levels of quality from excellent to poor. 
para o fornecimento de feedback; e, por fim, (3) uma estratégia de pontuação, que geralmente envolve uma escala que interpreta os julgamentos sobre determinado produto ou processo, servindo para o cálculo da nota final de um recorte específico do tempo escolar (REDDY; ANDRADE, 2010).

Em razão das características apontadas por Reddy e Andrade (2010), a utilização de descritores favorece a reescrita dos projetos numa perspectiva dialógica. Com critérios de avaliação e com uma estratégia de pontuação explicitados com clareza, os estudantes podem realizar a tarefa de escrever um projeto de pesquisa sabendo como serão avaliados e que itens devem estar presentes nos documentos elaborados por eles. Com definições de qualidade bem estabelecidas, a revisão dos textos pode ser feita tanto pelo professor como por outros estudantes, pois ofeedback servirá para apontar se o projeto atingiu, atingiu parcialmente ou se não atingiu os objetivos estabelecidos. Nesse sentido, os descritores também podem funcionar como bilhetes orientadores (MANGABEIRA; COSTA; SIMÕES, 2011). Segundo Mangabeira, Costa e Simões (2011), "a reescrita orientada por bilhetes constituise como uma maneira de avaliação dos textos que vai além do que se intitula correção indicativa" (p. 296), pois não se resume a apenas apontar os problemas do texto produzido pelo aluno, mas, numa "correção interativa" (p. 297), em que se privilegia o que o aluno quer dizer. Nessa perspectiva o professor media o processo de apropriação de um determinado gênero pelo aluno. No modelo dialógico de planejamento de projeto de pesquisa aqui proposto, esse papel de leitor interessado pode ser desempenhado tanto pelo professor como por outros alunos, pois os descritores para atingir os objetivos da tarefa são compartilhados e servem como bilhetes para orientar a reescrita.

Schlatter e Garcez (2012, p. 165-166) também parecem concordar com a relação proposta entre descritores e bilhetes orientadores. Ao elaborar tabelas com parâmetros de avaliação de leitura e escrita e de compreensão e produção oral, os autores propuseram descritores para "não cumpre a tarefa", para "cumpre a tarefa parcialmente" e para "cumpre a tarefa adequadamente". Para cada nível, os autores descreveram, em uma terceira coluna, uma recomendação de reescrita, relacionada com o descritor do nível seguinte. Apesar de não estar explícito no texto de Schlatter e Garcez (2012), essas recomendações seguem a proposta de escrita orientada por bilhetes (MANGABEIRA; COSTA; SIMÕES, 2011), pois enunciam "uma nova tarefa, explicitando para o aluno como deve proceder na reescrita de seu texto" (MANGABEIRA; COSTA; SIMÕES, 2011, p. 301).

$\mathrm{Na}$ ficha que apresentamos neste artigo, além dos descritores, também propomos um espaço (Figura 1) no qual o revisor, que pode ser professor ou aluno, 
é encorajado a redigir comentários que orientem o autor do projeto a como atingir plenamente os objetivos estabelecidos, "posicionando-se como um leitor que sugere mudanças, faz perguntas para esclarecer alguns pontos que não ficaram claros na leitura do texto" MANGABEIRA; COSTA; SIMÕES, 2011, p. 303). Ao comentar os projetos, o revisor coloca-se como um leitor interessado, que busca compreender o que o autor quis dizer e escreve sugestões para que todos os elementos do projeto possam ganhar o conceito de "atingido" (Quadro 1).

$O$ projeto de pesquisa enquanto gênero do discurso apresenta uma estrutura relativamente estável. Gil (2002), Marconi e Lakatos (2003) e Gerhardt et al. (2009) são exemplos de autores que apresentam sugestões de como organizar projetos. No entanto, essas obras são referências tradicionais utilizadas para a construção de projetos de pesquisa no ambiente universitário. Para o contexto onde este trabalho foi desenvolvido, interessam-nos autores que buscaram adaptar essas orientações para o contexto de pesquisa na educação básica e para projetos de feiras de ciências. Palacios (2016), ao adaptar o projeto de pesquisa para alunos de ensino médio, propôs a seguinte estrutura: tema ${ }_{i}$ justificativa $_{i}$ objetivos $_{i}$ perguntas de pesquisa ${ }_{i}$ hipóteses; metodologia; e tempo de duração. Já Nascimento e Ventura (2017) propuseram algumas etapas para projetos para feiras de ciências: título; equipe; situação-problema; objetivos; justificativa; metodologia; etapas; cronograma de trabalho; e orçamento. Por fim, a Feira de Ciências Univates sugere um modelo de plano de pesquisa ${ }^{10}$ contendo título, identificação do grupo, tema, problema, objetivos, justificativa, revisão bibliográfica, metodologia, materiais e reagentes (quando houver), cronograma, resultados esperados e referências.

Com base nesses autores e eventos, a estrutura do modelo aqui apresentado foi pensada para ser sintética e didática. Assim, propomos uma ficha para que os alunos possam elaborar seus projetos de pesquisa (Figura 1), contendo título, grupo de pesquisa, tema, justificativa, problema de pesquisa, objetivos, metodologia, resultados esperados, cronograma e referências. Pelo fato de a escola onde este estudo foi realizado não dispor de infraestrutura suficiente para que os alunos elaborem seus projetos em suporte digital, essa ficha foi pensada para que possa ser preenchida como suporte físico.

10. Disponível em: <https://www.univates.br/media/evento/feiradeciencias2018/modelo.doc $>$ Acesso em: 23 set. 2018. 


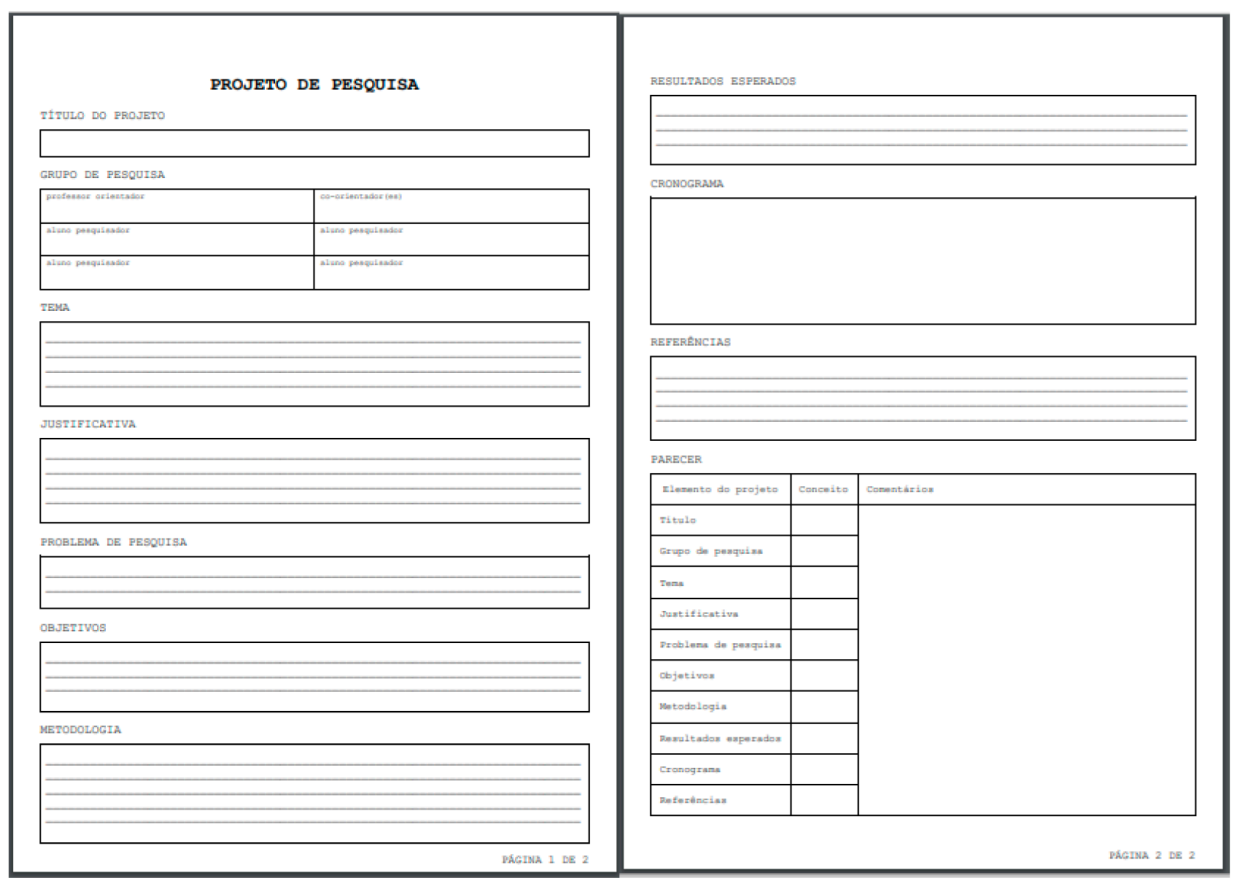

Figura 1. Ficha do projeto de pesquisa

A partir de uma leitura intensiva das orientações de Gil (2002, p. 161-170), Marconi e Lakatos (2003, p. 216-227), Bagno (2005, p. 26-42), Gerhardt et al. (2009), Souza et al. (2013, p. 21 -29), Palacios (2016, p. 232-233) e Nascimento e Ventura (2017, p.26-35), foram construídos descritores para cada um dos elementos do projeto de pesquisa, estabelecendo critérios para "atingido", "parcialmente atingido" e "não atingido" (Quadro 1). Essa divisão favorece uma estratégia de pontuação (REDDY; ANDRADE, 2010) que permite que critérios qualitativos, na medida do possível, possam ser quantificados para avaliação escolar. Além disso, essa estratégia também possui um caráter orientador, pois os descritores funcionam como bilhetes para orientar a reescrita (MANGABEIRA; COSTA; SIMÕES, 2011), permitindo que professores e estudantes estejam cientes sobre o que fazer para que um projeto passe de "atingido parcialmente" para "atingido", por exemplo. 


\begin{tabular}{|c|c|c|c|}
\hline $\begin{array}{l}\text { Elemento do } \\
\text { projeto }\end{array}$ & Atingido (A) & $\begin{array}{l}\text { Atingido parcialmente } \\
\text { (AP) }\end{array}$ & Não atingido (NA) \\
\hline Título & $\begin{array}{l}\text { - Informa o tema da } \\
\text { pesquisa de forma clara } \\
\text { e concisa; } \\
\text { - É criativo e original. }\end{array}$ & $\begin{array}{l}\text { - Informa o tema da } \\
\text { pesquisa de maneira } \\
\text { ampla. }\end{array}$ & $\begin{array}{l}\text { - Está confuso ou muito } \\
\text { extenso; } \\
\text { - Não apresenta título. }\end{array}$ \\
\hline $\begin{array}{l}\text { Grupo de } \\
\text { pesquisa }\end{array}$ & $\begin{array}{l}\text { - Apresenta até três } \\
\text { alunos pesquisadores; } \\
\text { - Apresenta um } \\
\text { professor orientador } \\
\text { e, opcionalmente, até } \\
\text { dois coorientadores. }\end{array}$ & $\begin{array}{l}\text { - Apresenta todos os } \\
\text { integrantes do grupo, } \\
\text { porém com nomes } \\
\text { incompletos. }\end{array}$ & $\begin{array}{l}\text { - Não apresenta os } \\
\text { nomes dos alunos } \\
\text { pesquisadores; } \\
\text { - Não apresenta um } \\
\text { professor orientador. }\end{array}$ \\
\hline Tema & $\begin{array}{l}\text { - Delimita, de maneira } \\
\text { clara e precisa, o } \\
\text { assunto que será } \\
\text { abordado na pesquisa. }\end{array}$ & $\begin{array}{l}\text { - Apresenta o assunto } \\
\text { da pesquisa de maneira } \\
\text { ampla. }\end{array}$ & $\begin{array}{l}\text { - Confunde a } \\
\text { delimitação do tema } \\
\text { com outra parte do } \\
\text { projeto. }\end{array}$ \\
\hline Justificativa & $\begin{array}{l}\text { - Contextualiza porque } \\
\text { o grupo escolheu } \\
\text { pesquisar o assunto. } \\
\text { - Argumenta sobre } \\
\text { a relevância da } \\
\text { pesquisa para a área } \\
\text { do conhecimento } \\
\text { relacionada. }\end{array}$ & $\begin{array}{l}\text { - Contextualiza por } \\
\text { que o grupo escolheu } \\
\text { pesquisar o assunto sem } \\
\text { defender a relevância } \\
\text { da pesquisa.. }\end{array}$ & $\begin{array}{l}\text { - Não contextualiza a } \\
\text { escolha do tema nem } \\
\text { argumenta sobre a } \\
\text { relevância da pesquisa. }\end{array}$ \\
\hline $\begin{array}{l}\text { Problema de } \\
\text { pesquisa }\end{array}$ & $\begin{array}{l}\text { - Apresenta uma } \\
\text { questão de pesquisa } \\
\text { delimitada, original } \\
\text { e que pode ser } \\
\text { respondida através } \\
\text { de pesquisa ou do } \\
\text { desenvolvimento de } \\
\text { uma técnica. }\end{array}$ & $\begin{array}{lr}\text { - Apresenta } & \text { um } \\
\text { problema } & \text { pouco } \\
\text { delimitado e } & \text { que } \\
\text { não necessita } & \text { da } \\
\text { produção de } & \text { novos } \\
\text { conhecimentos } & \text { ou } \\
\text { técnicas para } & \text { ser } \\
\text { resolvido; } & \\
\text { - Não aparece } \\
\text { necessariamente } & \text { em } \\
\text { forma de pergunta. }\end{array}$ & $\begin{array}{l}\text { - Apresenta um } \\
\text { problema muito } \\
\text { amplo, não passível de } \\
\text { investigação. }\end{array}$ \\
\hline
\end{tabular}




\begin{tabular}{|c|c|c|c|}
\hline Objetivos & $\begin{array}{l}\text { - Indica, de forma } \\
\text { clara e definida, a ação } \\
\text { a ser realizada para } \\
\text { resolver o problema } \\
\text { de pesquisa (ou com a } \\
\text { hipótese, caso houver), } \\
\text { começando com verbo } \\
\text { no infinitivo; } \\
\text { - Pode apresentar } \\
\text { objetivos específicos, } \\
\text { que detalham as etapas } \\
\text { da pesquisa, que } \\
\text { levarão ao objetivo } \\
\text { geral. }\end{array}$ & $\begin{array}{l}\text { - Inicia com verbo no } \\
\text { infinitivo, mas indica } \\
\text { uma ação que não está } \\
\text { claramente relacionada } \\
\text { com o problema de } \\
\text { pesquisa. } \\
\end{array}$ & $\begin{array}{l}\text { - Discorre sobre a } \\
\text { ação a ser realizada na } \\
\text { pesquisa sem observar } \\
\text { precisão e clareza e sem } \\
\text { iniciar com verbo no } \\
\text { infinitivo. } \\
\text { - Descreve etapas da } \\
\text { metodologia. }\end{array}$ \\
\hline Metodologia & 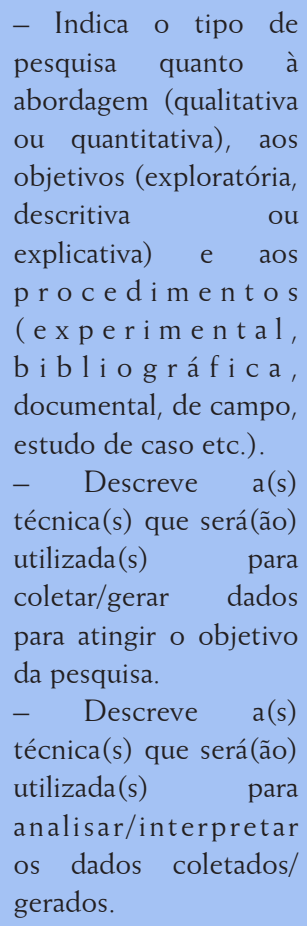 & $\begin{array}{l}\text { - Não indica o tipo de } \\
\text { pesquisa. } \\
\text { - Descreve brevemente } \\
\text { as etapas da pesquisa, } \\
\text { sem apresentar } \\
\text { detalhadamente as } \\
\text { técnicas de coleta/ } \\
\text { geração de dados e de } \\
\text { análise/interpretação } \\
\text { desses dados. }\end{array}$ & $\begin{array}{l}\text { - Menciona vagamente } \\
\text { algum procedimento a } \\
\text { ser realizado. }\end{array}$ \\
\hline $\begin{array}{l}\text { Resultados } \\
\text { esperados }\end{array}$ & $\begin{array}{l}\text { - Descreve a hipótese } \\
\text { ou a expectativa, } \\
\text { dependendo da opção } \\
\text { metodológica, de } \\
\text { como a pesquisa pode } \\
\text { responder ao problema } \\
\text { de pesquisa. }\end{array}$ & $\begin{array}{l}\text { - Descreve resultados } \\
\text { esperados, mas sem } \\
\text { expressa relação com o } \\
\text { problema de pesquisa. }\end{array}$ & $\begin{array}{l}\text { - Declara, de maneira } \\
\text { ingênua ou de forma } \\
\text { ampla, resolver um } \\
\text { problema impossível } \\
\text { com uma pesquisa (por } \\
\text { exemplo, acabar com o } \\
\text { racismo). }\end{array}$ \\
\hline
\end{tabular}




\begin{tabular}{|c|c|c|c|}
\hline Cronograma & $\begin{array}{l}\text { - Distribui adequa- } \\
\text { damente as etapas da } \\
\text { pesquisa em meses ou } \\
\text { semanas no formato de } \\
\text { uma tabela, detalhando } \\
\text { as fases de planejamen- } \\
\text { to, execução e sociali- } \\
\text { zação dos resultados. }\end{array}$ & $\begin{array}{l}\text { - Distribui as etapas de } \\
\text { pesquisa em meses ou } \\
\text { semanas sem detalhar as } \\
\text { fases de planejamento, } \\
\text { execução e socialização } \\
\text { dos resultados. }\end{array}$ & $\begin{array}{l}\text { - Distribui de maneira } \\
\text { inadequada ou não } \\
\text { distribui as etapas da } \\
\text { pesquisa em meses ou } \\
\text { semanas. }\end{array}$ \\
\hline Referências & $\begin{array}{l}\text { - Cita as referências } \\
\text { empregadas ao longo } \\
\text { do projeto segundo as } \\
\text { normas da ABNT. }\end{array}$ & $\begin{array}{l}\text { - Cita as referências do } \\
\text { projeto, mas sem seguir } \\
\text { as normas da ABNT. } \\
\text { - Cita as referências, } \\
\text { porém, nem todas estão } \\
\text { no corpo do projeto. }\end{array}$ & $\begin{array}{l}\text { - Cita sites de busca } \\
\text { como referência. } \\
\text { - Não cita referências, } \\
\text { ou cita parcialmente } \\
\text { (apenas nome dos } \\
\text { autores, por exemplo). }\end{array}$ \\
\hline
\end{tabular}

Quadro 1. Descritores dos elementos do projeto de pesquisa

Os parâmetros avaliativos acima propostos foram desenvolvidos com o objetivo de operacionalizar a primeira estratégia de avaliação formativa proposta por Black e Wiliam (2009, p.8): "esclarecer e compartilhar os propósitos de aprendizagem e critérios para sucesso". Assim, professores e alunos compartilham os critérios necessários para escrever um projeto de pesquisa com sucesso. Para pôr em prática a segunda estratégia, que é "desenvolver discussões eficazes em sala de aula e outras tarefas de aprendizagem que indiquem evidências da compreensão do aluno" (BLACK; WILIAM, 2009, p. 8), elaborou-se a ficha apresentada na Figura 1. Após ser discutida e relacionada aos descritores, os alunos, em seus grupos de pesquisa, preencherão com os dados da suas pesquisas projetadas.

A terceira estratégia, que propõe "fornecer feedback para que os alunos progridam" (BLACK, WILIAM, 2009, p. 8), pode ser realizada de diversas maneiras. Uma delas é o professor orientador de um determinado grupo de pesquisa realizar a leitura do projeto com vistas aos parâmetros avaliativos e, em um encontro com o grupo, discutir o texto para orientar a reescrita, caso necessário. O feedback também pode aparecer por escrito no campo de comentários da ficha e na classificação dos níveis descritos nos parâmetros de avaliação. Ainda há uma outra maneira que já operacionaliza também a quarta estratégia, "Tornar os alunos recursos instrucionais uns para os outros" (BLACK, WILIAM, 2009, p. 8). Como mencionado anteriormente, com o esclarecimento dos parâmetros de avaliação, os próprios alunos podem cumprir o papel de leitores interessados e, assim, fornecerem feedback para uma primeira reescrita. Assim, de maneira geral, pode-se dizer que o modelo dialógico de planejamento de projetos de pesquisa que é proposto e discutido neste artigo visa à prática da quinta e última estratégia de 
avaliação formativa, que é "tornar os alunos donos da sua aprendizagem" (BLACK; WILIAM, 2009, p. 8).

\section{CONSIDERAÇÕES FINAIS}

Neste artigo propomos um modelo dialógico para elaborar projetos de pesquisa no contexto de ensino fundamental na perspectiva do modelo de letramentos acadêmicos a fim de que os estudantes saibam identificar os conhecimentos valorizados na área de conhecimento do seu projeto. Também refletimos sobre a importância de se pensar a avaliação na sua dimensão formativa que privilegie o processo em relação aos resultados e que possa subsidiar decisões de professores e alunos.

A estratégia proposta neste trabalho é a utilização de parâmetros avaliativos claros e definidos, mais especificamente na forma de descritores de elementos de um projeto de pesquisa. Ao conhecer esses parâmetros antes mesmo de planejar os projetos, os alunos se tornam mais autônomos durante o processo de escrita e reescrita, pois sabem de antemão como serão avaliados e o que devem fazer para atingir os objetivos estabelecidos. Essa autonomia também se expressa na possibilidade de assumirem o papel de leitores interessados dos projetos uns dos outros, podendo comparar o projeto com os descritores e escrever pareceres.

Destacamos também que os parâmetros apresentados neste artigo foram construídos para o planejamento de projetos de pesquisa de uma escola municipal de ensino fundamental. Sendo assim, tanto a ficha (Figura 1) quanto os descritores (Quadro 1) aqui propostos podem ser adaptados para adequar às especificidades de outros contextos escolares ou para atender exigências de determinadas feiras de ciências ou programas de iniciação científica. Nesse sentido, é essencial comunicar a comunidade acadêmica, incluindo aqui a escola, sobre as potencialidades, os desafios e as limitações da proposta aqui apresentada bem como de suas alterações.

\section{$\overline{\text { REFERÊNCIAS }}$}

BAGNO, M. (2005). Pesquisa na Escola: o que é, como se faz. São Paulo: Edições Loyola.

BAKHTIN, M. (2003). Estética da criação verbal. São Paulo: Martins Fontes.

BLACK, P.; WILIAM, D. (1998). Assessment and Classroom Learning. Assessment in Education, v. 5, n. 1, pp. 07-74. 
BLACK, P.; WILIAM, D. (2009). Developing the theory of formative assessment. Educational Assessment, Evaluation and Accountability, v. 21, n. 1, p. 05-31.

BRASIL. (2017). Base Nacional Comum Curricular: educar é a base. Brasília: MEC/CONSED/ UNDIME. Disponível em: < http://basenacionalcomum.mec.gov.br/images/BNCC publicacao.pdf $>$. Acesso em: 06 out. 2018.

CLARK, H.H. (2000). O uso da linguagem. Cadernos de Tradução, Porto Alegre, n. 09, p. 49-71.

FISCHER, A. (2007). A construção de letramentos na esfera acadêmica. Tese (Doutorado em Linguística) - Programa de Pós-Graduação em Linguística, Universidade Federal de Santa Catarina, Florianópolis.

DILLI, C.; SCHOFFEN, J.R.; SCHLATTER, M. (2012). Parâmetros para a avaliação de produção escrita orientados pela noção de gêneros do discurso. In: SCHOFFEN, J. R.; KUNRATH, S. P.; ANDRIGHETTI, G. H.; SANTOS, L. G. (Org.) Português como Língua Adicional: Reflexões para a Prática Docente. 1 ed. Porto Alegre: Bem Brasil, p. 171-199.

GALLON, M.S.; ROCHA FILHO, J.B.; NASCIMENTO, S.S. (2017). Feiras de ciências nos ENPECs (1997-2015): identificando tendências e traçando possibilidades. In: Encontro Nacional de Pesquisa em Educação em Ciências, 6., Florianópolis. Anais... Florianópolis: ABRAPEC, 2017. Disponível em: < $\underline{\text { http://www.abrapecnet.org.br/ }}$ enpec/xi-enpec/anais/resumos/R1722-1.pdf > . Acesso em: 06 out. 2018.

GALLON, M.S.; SILVA, C.M.; MADRUGA, Z.E.F. (2018). O papel do professor orientador na visão de um grupo de estudantes de ensino médio. Revista Olb@res, São Paulo, v. 6, n. 1, p. 164-180.

GERHARDT, T.E.; RAMOS, I.C.A.; RIQUINHO, D.L.; SANTOS, D.N. (2009). Unidade 4: estrutura do projeto de pesquisa. In: GERHARDT, T. E.; SILVEIRA, D. T. (Orgs.). Métodos de Pesquisa. Porto Alegre: Editora da UFRGS, p. 65-88.

GIL, A.C. (2002). Como elaborar projetos de pesquisa. 4 ed. São Paulo: Atlas.

GONÇALVES, A.A.G.; SILVA, C.S.R.; BREGUNCI, M.G.; CASTANHEIRA, M.L.; MONTEIRO, S.M. (2008). Alfabetização e Letramento: Questões sobre Avaliação. In: BRASIL. Pró-Letramento: Programa de Formação Continuada de Professores dos Anos/Séries Iniciais do Ensino Fundamental: alfabetização e linguagem. Brasília: MEC/SEB, p. 01-50. 
GONÇALVES, T.V.O. (2011). Feiras de Ciências e formação de professores. In: PAVÃO, A. C.; FREITAS, D. (Org.) Quanta ciência bá no ensino de ciências. São Carlos: EDUFSCAR, p. 207-216.

LEA, M.R.; STREET, B.V. (1998). Student writing in higher education: an academic literacies approach. UK Studies in Higher Education, v. 23, n. 2, p. 157-172.

LEA, M.R.; STREET, B.V. (2006). The "Academic Literacies" Model: Theory and Applications. Theory into Practice, v. 45, n. 4, p. 368-377.

MANCUSO, R.; LEITE FILHO, I. (2006). Feiras de Ciências no Brasil: uma trajetória de quatro décadas. In: BRASIL. Ministério da Educação. Programa Nacional de Apoio às Feiras de Ciências da Educação Básica Fenaceb. Brasilia: MEC/SEB. Disponível em: < http://portal. mec.gov.br/seb/arquivos/pdf/EnsMed/fenaceb.pdf> . Acesso em: 20 out. 2018.

MANGABEIRA, A.B.A.; COSTA, E.V.; SIMÕES, L.J. (2011). O Bilhete Orientador: um gênero discursivo em favor da avaliação de textos na aula de línguas. Cadernos do IL, Porto Alegre, n. 42, p. 293-307.

MARCONI, M.A.; LAKATOS, E.M. (2003). Fundamentos de Metodologia Científica. São Paulo: Editora Atlas.

NASCIMENTO, S.S.; VENTURA, P.C.S. (2017). Projetos Escolares para Feiras de Ciências. Belo Horizonte: Rolimã.

NICOL, D.J.; MACFARLANE-DICK, D. (2006). Formative assessment and self-regulated learning: a model and seven principles of good feedback practice. Studies in Higher Education, v. 31, n. 2, p. 199-218.

PALACIOS, G. G. (2016). Letramento acadêmico no ensino médio: uma experiência pedagógica a partir do material didático autoral "Manual do Jovem Pesquisador. Dissertação (Mestrado Profissional em Ensino de Línguas) - Universidade Federal do Pampa, Bagé.

REDDY, Y.M.; ANDRADE, H. (2010). A review of rubric use in higher education. Assessment \& Evaluation in Higher Education, v. 35, n. 4, p. 435-448.

RIBEIRO, F.A.S. (2015). Como organizar uma feira de ciências. Natal: Infinita Imagem.

SADLER, D.R. (1998). Formative assessment: revisiting the territory, Assessment in Education, v. 5. n. 1, p. 77-84. 
SCHLATTER, M.; GARCEZ, P.M. (2012). Linguas Adicionais na Escola: aprendizagens colaborativas em inglês. Erechim: Edelbra.

SOUZA, D.I.; MÜLLER, D.M.; FRACASSI, M.A.T.; ROMEIRO, S.B.B. (2013). Manual de Orientações para Projetos de Pesquisa. Novo Hamburgo: FESLSVC. Disponível em: $<$ http://www.liberato.com.br/sites/default/files/manual_de_orientacoes_para projetos de pesquisa.pdf $>$. Acesso em: 15 out. 2018.

STREET, B.V. (1984). Literacy in Theory and Practice. Cambridge: Cambridge University Press.

WILIAM, D. (2007). Keep learning on track: classrooms assessment and the regulation of learning. In: LESTER, F. K. Second Handbook of Research on Mathematics Teaching and Learning. (Org.). Charlotte: Information Age Publishing, p. 1051-1098.

WILIAM, D. (2011). Embedding Formative Assessment. Bloomington: Solution Tree Press.

Recebido: 6/11/2018

Aceito: 8/04/2019

Publicado: 7/08/2019 